\title{
Uji Aktivitas Adsoben Karbon Aktif Tempurung Kelapa Termodifikasi dengan Active Site $\mathrm{Fe}_{2} \mathrm{O}_{3}$
}

\author{
Shinta Amelia ${ }^{\mathrm{a}, 1, *}$, Zahrul Mufrodi ${ }^{\mathrm{a}, 2}$ \\ ${ }^{a}$ Program Studi Teknik Kimia, Fakultas Teknologi Industri, Universitas Ahmad Dahlan Kampus IV, Jl. Ringroad Selatan, Tamanan, Banguntapan, Bantul, \\ D.I Yogyakarta 55164 \\ ${ }^{1}$ shinta.amelia@che.uad.ac.id*; ${ }^{2}$ zahrul.mufrodi@che.uad.ac.id \\ * corresponding author
}

Article history

Received January 02, 2019

Revised April 14, 2019

Accepted April 16, 2019

Keywords

activated carbon

adsorption

iron oxide

\section{ABSTRACT}

The use of dyes in the textile industry has a negative impact, namely water pollution if the waste is discharged directly into the river or not treated properly. Liquid waste from the textile industry generally still contains dyes that are harmful to living things and the environment. In this study the dye adsorption method was used by using modified activated carbon from the coconut shell with the addition of the active site $\mathrm{Fe}_{2} \mathrm{O}_{3}$. Characterization and activity testing of iron / porous oxide activated carbon adsorbent will be carried out. The type of porous activated carbon used is coconut shell carbon with micropore characters. The stages of this study consisted of the impregnation process of iron oxide on porous carbon, the methylene blue adsorption process and the characterization of the resulting adsorbent. Based on the research that has been done, it can be concluded that the adsorption of $\mathrm{Fe}_{2} \mathrm{O}_{3}$ / coconut shell activated carbon is very effectively applied for the absorption of dye wastewater. The adsorption capacity of methylene blue increased with increasing concentrations of loading of active sites of $\mathrm{Fe}$ and the percentage of adsorption capacity in the 180 minutes reaction was $89.8 \%$ with the loading of iron oxide / coconut shell adsorbent $2 \%$. In addition, from the results of the adsorbent activity test with variations in the mass addition of the adsorbent it can be concluded that the mass increase of the adsorbent significantly affected the yield of blue methylene adsorption.

This is an open access article under the CC-BY-SA license.

\section{Pendahuluan}

Industri tekstil menggunakan zat warna dalam proses produksi untuk menghasilkan tekstil dengan kualitas yang baik. Namun, penggunaan zat warna dalam industri tekstil memberikan dampak negatif, yaitu pencemaran air jika limbah dibuang ke sungai secara langsung ataupun tidak diolah dengan baik. Limbah cair dari industri tekstil umumnya masih mengandung zat warna yang berbahaya bagi makhluk hidup dan lingkungan. Zat warna biasanya merupakan struktur molekul aromatik kompleks yang membuat mereka sangat tahan terhadap biodegradasi dengan proses perlakuan oksidasi fisik dan biologis konvensional [1]. Terdapat berbagai macam metode yang dapat digunakan untuk menghilangkan zat warna, antara lain flokulasi, koagulasi, presipitasi, adsorpsi, filtrasi dengan membran, teknik elektrokimia, ozonisasi, dan dekolorisasi [2]. Dalam penelitian ini digunakan metode adsorpsi zat warna dengan menggunakan karbon aktif tempurung kelapa yang telah dimodifikasi menggunakan active site $\mathrm{Fe}_{2} \mathrm{O}_{3}$. Hasil dari penelitian ini nantinya akan digunakan pada penelitian selanjutnya yakni proses simultan antara adsorpsi dan reaksi fenton menggunakan katalis heterogen untuk degradasi limbah zat warna. 
Metode impregnasi merupakan salah satu metode pembuatan katalis berupa pengisian logam ke dalam rongga pori dengan cara mengkontakkan padatan yang terlarut dalam pelarut ke dalam rongga pori agar dapat terikat pada permukaan penyangga seperti zeolit, silica gel, karbon, dll. Ada beberapa jenis metode impregnasi salah satunya yaitu wet impregnation method. Metode ini adalah proses pembuatan katalis dimana volum larutan yang digunakan lebih besar dari volum pori penyangga [3]. Tahap pertama adalah mengontakkan larutan garam logam pada permukaan karbon. Proses dilanjutkan dengan pengeringan dan kalsinasi untuk menguapkan komponen-komponen yang mudah menguap sehingga metal sebagai situs aktif akan terikat pada permukaan penyangga. Metal oksida merupakan katalis yang dapat digunakan dalam proses oksidasi zat warna. Metal oksida yang dapat digunakan seperti $\mathrm{Fe}_{2} \mathrm{O}_{3}$ dan $\mathrm{Ce}_{2} \mathrm{O}_{3}$ [4]. Dalam penggunaannya metal oksida dapat digunakan dalam bentuk nanopartikel ataupun diembankan dalam material pengemban (support material). Dari sisi kemudahan separasi metal oksida teremban dalam material berpori memiliki keunggulan. Karbon berpori merupakan sebuah kandidat yang sangat baik sebagai bahan pengemban karena luas permukaan tinggi dan stabilitas kimia yang sangat baik [2].

Pada penelitian ini, karakterisasi dan uji aktivitas adsorben besi oksida/karbon aktif berpori akan dilakukan. Jenis karbon aktif berpori yang digunakan yaitu karbon tempurung kelapa dengan karakter mikropori. Karbon berpori karena sifat kestabilan fisika dan kimia yang baik dan luas permukaan yang tinggi $\left(500-2000 \mathrm{~m}^{2} / \mathrm{g}\right)$ merupakan katalis support yang sangat potensial [5].

\section{Metodologi}

\subsection{Alat dan Bahan}

Alat-alat yang digunakan pada penelitian ini antara lain, pompa vakum, thermometer, pemanas mantel, labu leher tiga, beaker glass dan magnetic stirer. Sedangkan bahan- bahan yang digunakan dalam penelitian ini adalah karbon tempurung kelapa. $\mathrm{Fe}\left(\mathrm{NO}_{3}\right)_{3} .9 \mathrm{H}_{2} \mathrm{O}(99 \%$, Merk) dan isopropanol ( $97 \%$ analytical grade, Bratacem) masing-masing digunakan sebagai prekursor besi dan solvent. Dalam reaksi Fenton, methylene blue (95\% analytical grade, Sigma Aldrich) digunakan sebagai limbah simulasi. Struktur pori dari karbon dikarakterisasi dengan mengunakan $\mathrm{N}_{2}$-sorption analyzer (Nova 2000, Quantachrome). UV/Vis spektrofotometer (Shimadzu Mini 1240) digunakan untuk menganalisa konsentrasi methylene blue per satuan waktu.

\subsection{Proses Impregnasi Oksida Besi pada Permukaan Karbon Berpori}

Sebanyak 2 gram karbon aktif yang telah dioven dimasukkan dalam botol sampel. Larutan garam $\mathrm{Fe}\left(\mathrm{NO}_{3}\right)_{3} .9 \mathrm{H}_{2} \mathrm{O}$ ditambahkan sesuai variabel loading $\mathrm{Fe}(0,5 \%, 1 \%$, atau $2 \%)$ ke dalam botol sampel yang telah berisi karbon aktif. Campuran larutan garam $\mathrm{Fe}\left(\mathrm{NO}_{3}\right)_{3} \cdot 9 \mathrm{H}_{2} \mathrm{O}$ dengan karbon aktif kemudian diaduk selama 1 jam dengan ultrasonikator. Setelah proses evaporasi pada suhu ruangan selanjutnya karbon tersebut dioven pada suhu $60{ }^{\circ} \mathrm{C}$. Proses kalsinasi kemudian dilakukan pada suhu $300^{\circ} \mathrm{C}$ selama 3 jam dengan aliran $\mathrm{N}_{2}$ inert.

\subsection{Proses Adsorpsi Zat Warna}

Sebanyak $200 \mathrm{ml}$ larutan methylene blue dengan konsentrasi 20 ppm disiapkan dalam beaker glass. Larutan diaduk dengan magnetic stirrer pada kecepatan konstan $450 \mathrm{rpm}$ dan suhu ruang 30 ${ }^{\circ} \mathrm{C}$. Selanjutnya 0,025 gram adsorben $\mathrm{Fe}_{2} \mathrm{O}_{3}$ /karbon aktif dengan variabel loading masing-masing dimasukkan kedalam beaker glass yang telah berisi larutan methylene blue. Sebanyak $2 \mathrm{ml}$ larutan sampel diambil tiap selang waktu tertentu selama 3 jam. Selanjutnya konsentrasi methylene blue dalam larutan (C) tiap selang waktu tertentu dianalisis dengan Spektrofotometer UV-VIS pada panjang gelombang $663 \mathrm{~nm}$.

\subsection{Metode Analisis}

Data hasil adsorpsi dianalisis menggunakan spektrometer UV VIS dengan panjang gelombang $\lambda=663 \mathrm{~nm}$. Data hasil analisa tersebut digunakan untuk perhitungan konsentrasi methylene blue dalam cairan $\left(\mathrm{C}_{\mathrm{AL}}\right)$. 


\section{Hasil dan pembahasan}

\subsection{Karakterisasi Adsorben $\mathrm{Fe}_{2} \mathrm{O}_{3} / \mathrm{Karbon}$ Aktif}

Karakteristik dari karbon aktif tempurung kelapa berpori meliputi luas permukaan spesifik, diameter pori rata-rata dan volume pori dapat dilihat pada Tabel 1 . Tabel tersebut menunjukkan bahwa karbon berpori tempurung kelapa merupakan karbon mikropori (klasifikasi IUPAC) dengan diameter rerata yaitu $1,82 \mathrm{~nm}$.

Table 1. Karakteristik karbon tempurung kelapa [6].

\begin{tabular}{|c|c|}
\hline Karakter & Nilai \\
\hline Luas permukaan spesifik $\left(\mathrm{S}_{\mathrm{BET}}\right), \mathrm{m}^{2} / \mathrm{gram}$ & 1320 \\
\hline Luas mikropori $\left(\mathrm{S}_{\mathrm{mic}}\right), \mathrm{m}^{2} /$ gram & 1220 \\
\hline$\% \mathrm{~S}_{\mathrm{mic}}$ & 92 \\
\hline Total volume pori, $\mathrm{cm}^{3} /$ gram & 0,60 \\
\hline Volume mikropori $\left(\mathrm{V}_{\mathrm{mic}}\right), \mathrm{cm}^{3} / \mathrm{gram}$ & 0,45 \\
\hline$\% \mathrm{~V}_{\text {mic }}$ & 75 \\
\hline Diameter pori rata-rata, $\mathrm{nm}$ & 1,82 \\
\hline
\end{tabular}

Distribusi ukuran pori dihitung dengan model Quenched Solid State Functional Theory (QSDFT). Pada gambar 1 terlihat bahwa distribusi pori dengan ukuran dibawah $2 \mathrm{~nm}$ sangat dominan. Berdasarkan hasil distribusi pori semakin memperkuat bahwa karbon berpori tempurung kelapa merupakan karbon mikropori (klasifikasi IUPAC).

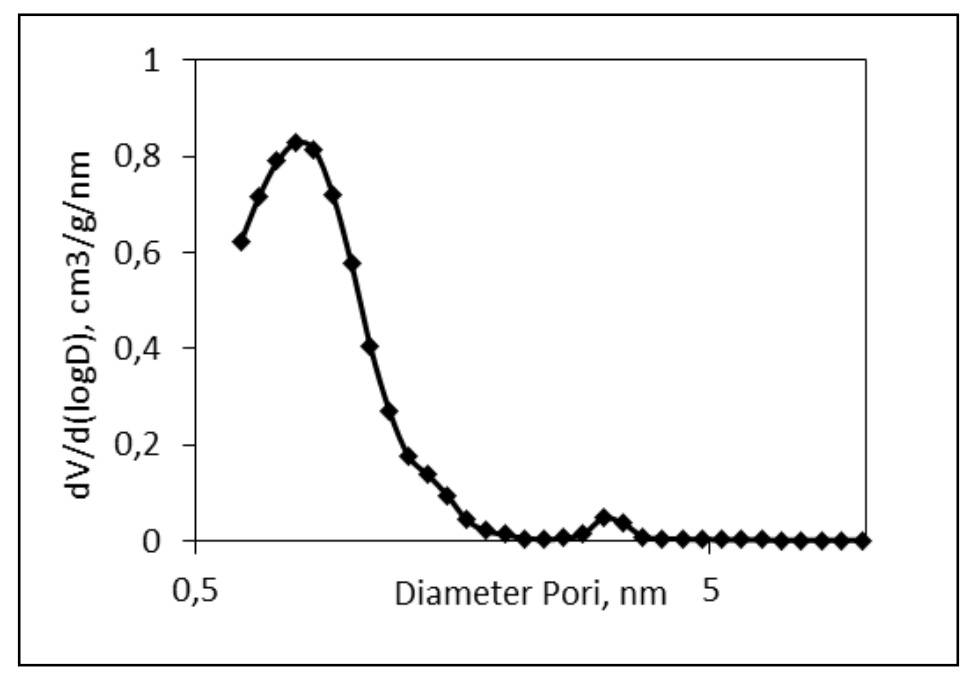

Gambar 1. Distribusi ukuran pori dengan QSDFT-N ${ }_{2}$ model [6].

Pembuatan adsoben $\mathrm{Fe}_{2} \mathrm{O}_{3} /$ Karbon aktif diawali dengan impregnasi precursor, yakni Fe ke dalam permukaan pori karbon. Dari segi ukuran ion besi (194 pm, hydrate), ion ini dapat masuk ke dalam pori-pori karbon berbasis tempurung kelapa tersebut. Proses impregnasi diawali dengan mengontakkan larutan logam pada permukaan karbon. Proses selanjutnya adalah pengeringan dan kalsinasi untuk pembentukan oksida besi. Distribusi oksida besi pada permukaan karbon merupakan aspek yang cukup penting dalam proses impregnasi oksida besi pada permukaan karbon. Distribusi logam yang merata pada permukaan karbon akan memaksimalkan proses penjerapannya. Hasil analisa morfologi katalis menggunakan Scanning Electron Microscopy - Energy Dispersive X-Ray Spectroscopy (SEM-EDX) dapat dilihat pada Gambar 2.(a). Sedangkan hasil distribusi logam pada permukaan karbon dapat dilihat pada Gambar 2.(b). Warna biru pada gambar menunjukkan elemental mapping keberadaan Fe pada permukaan karbon [7]. Dari gambar dapat dilihat bahwa oksida besi dapat tersebar cukup baik pada permukaan karbon tempurung kelapa tersebut. 


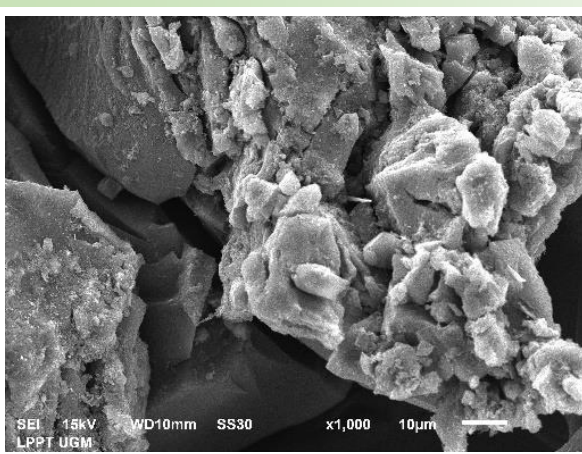

(A)

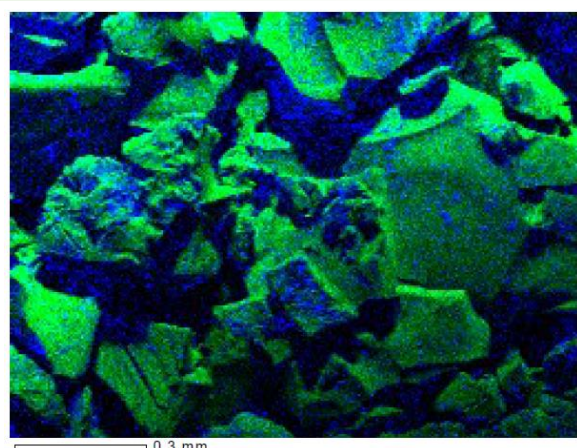

(B)

Gambar 2. (a) SEM untuk adsorben $\mathrm{Fe}_{2} \mathrm{O}_{3} /$ karbon aktif tempurung kelapa (b) Elemental Mapping C$\mathrm{Fe}$

\subsection{Hasil Uji Aktivitas Adsorben}

Kemudian untuk mengetahui aktivitas adsorben terhadap zat warna, adsorben digunakan untuk proses adsorpsi methylene blue. Hal tersebut penting dilakukan untuk menunjukkan daya serap dari karbon setelah adanya loading $\mathrm{Fe}$ pada permukaan karbon aktif tempurung kelapa tersebut. Tabel 2 menunjukkan persentase penjerapan methylene blue pada berbagai adsorben dengan loading Fe yang berbeda-beda pada waktu adsorpsi 180 menit. Adsorpsi tertinggi didapat pada sampel dengan konsentrasi loading $\mathrm{Fe}$ sebesar $2 \%$ dengan kapasitas adsorpsi sebesar 89,8\%. Hal tersebut kemungkinan diakibatkan oleh jumlah Fe yang cukup banyak dan berkontribusi positif terhadap peningkatan kapasitas adsorpsi methylene blue [8].

Table 2. Pengaruh loading Fe terhadap kapasitas adsorpsi methylene blue

\begin{tabular}{cc}
\hline Variasi loading Fe (\% massa) & Kapasitas Adsorpsi (\%) \\
\hline $0,5 \%$ & 88,1 \\
$1 \%$ & 89,4 \\
$2 \%$ & 89,8 \\
\hline
\end{tabular}

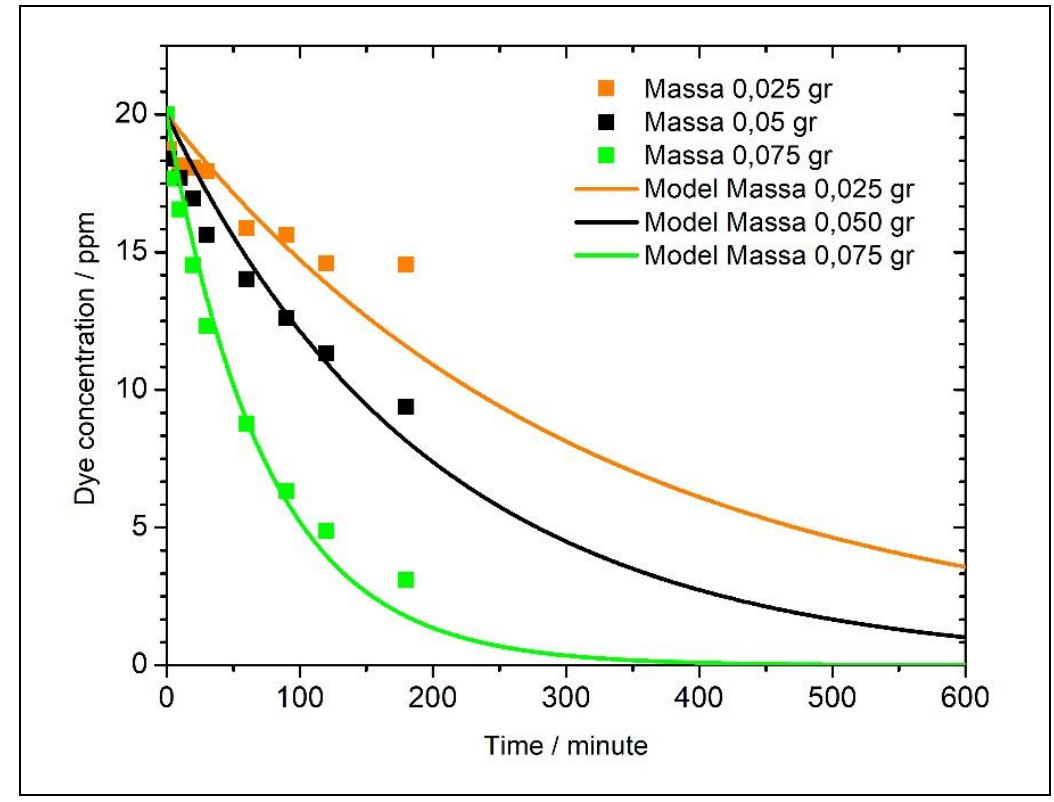

Gambar 3. Kapasitas adsorpsi methylene blue dengan variasi massa adsorben

Pada penelitian ini juga mempelajari pengaruh penambahan massa terhadap kapasitas adsorpsi methylene blue yakni $16 \mathrm{mg} / 100 \mathrm{mg}$ adsorben dengan konsentrasi active site bervariasi mulai dari 
0,5\%, $1 \%$ dan $2 \% \mathrm{Fe}$. Dari Gambar 3 diketahui bahwa semakin bertambahnya massa adsorben yang digunakan maka kapasitas adsorpsi methylene blue akan semakin besar. Hal ini dikarenakan jumlah massa adsoben semakin banyak sehingga methylene blue yang dapat terjerap juga semakin banyak. Selain itu hal tersebut juga dikarenakan tersedianya luas permukaan yang lebih besar pada sampel dengan jumlah adsorben yang lebih besar sehingga lebih banyak zat warna yang teradsorpsi [9].

\section{Kesimpulan}

Berdasarkan penelitian yang telah dilakukan dapat disimpulkan bahwa adsorben $\mathrm{Fe}_{2} \mathrm{O}_{3} / \mathrm{Karbon}$ aktif tempurung kelapa sangat efektif diaplikasikan untuk penjerapan limbah zat warna. Adsorpsi methylene blue meningkat dengan naiknya konsentrasi Fe loading dan hasil persentase kapasitas adsorpsi pada 180 menit sebesar 89,8\% dengan Fe loading sebesar 2\% oksida besi/karbon aktif tempurung kelapa. Selain itu, dari hasil uji aktivitas adsorben dengan variasi penambahan massa adsorben dapat disimpulkan bahwa peningkatan massa adsorben secara signifikan berpengaruh terhadap hasil penjerapan methylene blue.

\section{Ucapan Terimakasih}

Kami mengucapkan terimakasih kepada Prof. Ir. Wahyudi Budi Sediawan, S.U., Ph.D. beserta Dr-Ing. Teguh Ariyanto, S.T., M.Eng. dari Departemen Teknik Kimia Universitas Gadjah Mada yang telah membimbing dan mengarahkan kami dalam melaksanakan penelitian ini.

\section{Daftar Pustaka}

[1] Fayazi, M., Taher, M.A., Afzali,D., Mostafavi, A., 2016, Enhanced Fenton Like Degradation of Methylene Blue by Magnetically Activated Carbon/Hydrogen Peroxide with Hydroxylamine as Fenton Enhancer, Journal of Molecular Liquids, 216, 781-787.

[2] Hameed, B.H., Ahmad, A.A., Aziz, N., 2007, Isotherm, kinetics and thermodynamics of acid dye adsorption on activated palm ash, ChemicalEngineering Science,133, 193-203.

[3] Haber, J., Block, J.H. dan Delmon, B., 1995, Manual of Methods and Procedures for Catalyst Characterization, Pure \& Appl. Chem., Vol. 67,1257- 306.

[4] Castro, C.S., Guerreiro, M.C., Oliveira, L.C.A., Goncalves, M., Anastacio, A.S., 2009, Iron Oxide Dispersed Over Activated Carbon : Support Influence on The Oxidation of The Model Molecule Methylene Blue, Applied Catalysis A : General, Vol.367, 53-58.

[5] Prasetyo, I., Rochmadi, Ariyanto, T., Yunanto, R., 2013, Simple Method to Produce Nanoporous Carbon for Various Applications by Pyrolysis of Specially Synthesized Phenolic Resin, Indo. J. Chem, 13(2), 95-100

[6] Amelia,S., Sediawan, W.B., Prasetyo,I., Ariyanto, T., 2017, Degradasi Limbah Zat Warna dengan Katalis Karbon Aktif Teremban Oksida Besi, Prosiding Seminar Nasional Sains dan Teknologi, Vol. 1 No. 1, 24-29.

[7] Han, Zhantao., Sani, Badruddeen., Mrozik, Wojciech., Obst, Martin., Beckingham, Barbara., K.,Hrissi.,Werner, David., 2015, Magnetite Impregnation Effects on The Sorbent Properties of Activated Carbons and Biochars, Water Research, 70, 394-403.

[8] Mukti, N.I.F., Prasetyo, I., dan Mindaryani, A., 2015, Preparasi Karbon Teremban Oksida Cobalt dari Limbah Kulit Manggis sebagai Adsorben Penjerap Etilen untuk Pengawetan Buah, Reaktor, 15(3), 165 174.

[9] Sutrisno, B., Hidayat, A., Mufrodi, Z., 2014, Modifikasi Limbah Abu Layang menjadi Adsorben untuk Mengurangi Limbah Zat Warna pada Industri Tekstil, Jurnal Chemica, Vol. 1 No. 2, 57-66. 